\title{
A Brief Analysis of Inheritance of Traditional Chinese Culture in Modern Indoor Design
}

\author{
Yu $\operatorname{Lan}^{1}$ \\ ${ }^{1}$ Department of Art Design, Jiangyin Polytechnic College, Jiangyin, Jiangsu 214433
}

Key Words: Traditional culture, Indoor design, Inheritance, Reform, Innovation

\begin{abstract}
. with the rapid development and progress of economy, people's living standards and living quality keep improving. People tend to pursue a kind of cozy and comfortable living environment and thus have stricter and stricter requirements of indoor decoration. Indoor design styles of modern architecture are different. However, it is getting closer and closer to the traditional culture. This paper first makes a related overview of the traditional Chinese culture; combing with the development conditions of modern indoor design, it analyzes the relations between traditional Chinese culture and modern indoor design. Then this paper analyzes and explores the great significance of inheritance of traditional Chinese culture in modern indoor design. Finally, it summarizes the actual application of the traditional Chinese cultural elements in modern indoor design from the perspective of Confucianism thoughts, Taoism thoughts and Buddhism thoughts so as to boost inheritance of traditional Chinese culture and strengthen influence of ethnic culture.
\end{abstract}

\section{Research Background and Purpose}

With the constant development of social economic market, people has attached more and more importance to indoor design and decoration, which boosts the growth and development of decoration industry and also proposes substantial requirements of indoor design; it is of great necessity in order to strengthen innovation off indoor design. This research aims to explore the relations between the traditional Chinese culture and contemporary indoor design. Through combing different people's requirements of indoor design and the actual conditions of decoration industry and from the perspective of traditional Chinese culture, this paper analyzes the modern indoor design process so as to improve indoor design and decoration style and levels. Meanwhile, hope this research can provide related materials and experience for the application of traditional Chinese culture in modern indoor design and show the orientation for reform and innovation in modern indoor design field.

Under the large environment where the period feel and expressive force is sufficient, indoor decoration chooses to take advantage of the traditional Chinese cultural factors to design, which is one of its important development powers in breakthrough and innovation. Application of traditional culture in indoor design can both satisfy the internal spiritual pursuits of user groups and inherit and develop the traditional cultures, which is of important realistic significance. Therefore, this paper makes deeper analysis and research of traditional Chinese culture in modern indoor design so as to enrich the demands of indoor design, satisfy the inspirational demands of indoor designers and bring challenging significance to decoration design. Meanwhile, it is of importance cultural guidance significance and transitional historical significance to the long-term development of indoor design industry in our country.

\section{Related Overview of Traditional Chinese Culture}

Traditional culture is owned by the Chinese nations and is an organic system taking Confucianism ideologies as the datum line and covering the cultural contents and themes of various different ideologies. In a word, the traditional Chinese culture that boasts a history of 5000 years is broad and profound. Chinese culture bears the civilization of thousands of years, which reflects the national features and appearances.

Traditional Chinese culture refers to the Chinese culture in the inheritance process, which shows 
the objective reality and existence of Chinese culture in terms of historical inheritance. It is the most valuable cultural heritage in Chinese culture. Traditional culture attaches importance to the internal features absorbed or eliminated by domestic culture in the inheritance process. Traditional Chinese culture has abundant connotations and various forms. It is the valuable treasure of the global cultural resources, including artistic and craft works such as colored pottery and patterns, carved beams and painted affairs, folk paintings and wood carvings. Its resources are abundant and broad, having the unique beauty of visual language and artistic conception in the Orient and fully embodying the wisdom fruits of ancient Chinese. Application of traditional Chinese culture in indoor design is one way of internally inheriting and carrying forward the Chinese cultures.

\section{Relation between Indoor Design and Traditional Culture}

Indoor Design Reflects the Connotation of Traditional Culture. Indoor design can reflect the integral cultural appreciation awareness of the society. Indoor design activities are based on certain traditional cultural foundation. Fundamental requirement for indoor designers is to master the related cultures. Indoor design is closely related to the specific traditional cultural atmosphere and environments; its composition reflects the special feature of traditional cultures. Meanwhile, it is also the form of spreading different cultural concepts and aesthetic concepts, which can embody the cultural appearances and spiritual appearances of the specific age. The indoor design of different stages has direct or indirect relations with the traditional cultures. For the design form, traditional culture is the fresh blood that enriches its connotation.

Impact of Traditional Culture on the Development of Indoor Design. Although the times keeps making progress and developing, the design idea of indoor designers also keeps developing towards the modernized orientation. The design thoughts become more and more popular and fashionable. Yet inheritance of traditional cultures is the invariable main theme of indoor design. Indoor designers often regard the traditional culture as the inspiration source of design or the creation form and take it as the fundamental elements to define and deduce the process of indoor design. The traditional culture influences the development of indoor design to a great extent. Any component of the traditional culture can become the important factor that influences indoor design. The traditional culture influences the representation methods, tenets and aesthetic concepts of indoor design, which boost indoor design to combine the internal connotation of traditional culture so as to make modern design composition.

Traditional Culture and Indoor Design Integrate and Boost Each Other. The progress of scientific technologies and modernization of network bring formal convenience to indoor design to a great extent and also endow the works of indoor design with stronger period feel. However, enrichment of works forms cannot truly satisfy the higher requirements of the works contents and features. Indoor designers should integrate the modernized elements into indoor design and also attach importance to inheritance of traditional Chinese culture. They have to start from the perspective of the humanity and make the traditional culture stand out in modern indoor design works. In nature, traditional culture and indoor design of each era has a kind of close relation of mutual combination and mutual boost. The traditional culture boosts the forward development of indoor design to a certain degree; on the other hand, it is combined into the indoor design works and is the special inheritance of traditional Chinese culture. And indoor design applies the connotation of the traditional culture and present works of period feel so as to satisfy the pursuits of more and more groups to the connotation of traditional cultures.

\section{Inheritance Significance of Traditional Chinese Culture in Modern Indoor Design}

Significance of Modern Indoor Design to Inheritance of Traditional Chinese Culture. In works of indoor design, scientific application of traditional Chinese cultural elements can effectively inherit traditional Chinese culture. Hence it is of important historical significance and modern significance. With the social progress and the transition of the times, traditional Chinese culture has gradually been forgotten by compatriots, who show conflict emotions to traditional Chinese culture 
more or less. The works of indoor design shows the broad and profound traditional culture of our country and enables the compatriots to have deeper understanding and cognition of the traditional culture, which publicizes the traditional culture to a large extent and deepens the spread scope and influence of traditional Chinese culture. Inheritance of Chinese culture can guarantee the sustainable development of the society and the nation and can help the nation maintain the independent spiritual state, which is of major strategic significance to the development and prosperity of the entire Chinese nation.

Traditional Culture Greatly Improves the Aesthetic Significance of Modern Indoor Design Works. Modern indoor design works attach more and more importance to addition of traditional Chinese cultural elements, which is not only the requirement of the times, but also the necessary choice and appeal. In order to better satisfy the pursuits of clients, modern indoor design works tend to refine and apply the elements of traditional Chinese culture, endowing the indoor design works with more times characteristics and greatly improving the tastes of modern indoor design works. Application of traditional Chinese cultural elements to modern indoor design can improve people's aesthetic tastes and show the traditional spirits of design thoughts. It is an important reform and innovation for indoor design. It can boost the wide spread of the modern indoor design thoughts and boost the development of modern indoor design industry.

\section{Thought of Actual Application of Traditional Culture Essence in Modern Indoor Design}

Traditional Chinese culture is of long standing, including various schools. In its evolution process of over 5000 years, Confucianism, Taoism and Buddhism can greatly boost the prosperity and development of Chinese culture.

Application of Confucianism Thoughts. The core content in Confucianism is the golden mean. It emphasizes the philosophical concept that man and nature should be in harmony, which becomes the foundation of design idea that indoor designers adhere to. The starting point of many works attaches great importance to application of natural elements and pays attention to aesthetic taste that man and nature should be in harmony. Meanwhile, the golden mean of Confucianism is fully used in indoor design. Modern people pursue a kind of conciseness in the flamboyant decoration so as to make indoor decoration more profound in terms of spirits.

Application of Taoism Thoughts. Taoism attaches great importance to the idea 'the tao way follows nature' and emphasizes the idea 'let the nature take its course'. Indoor design applies this traditional element of Taoism thoughts and designers mainly create a kind of fluid space so as to enrich the connotation of the decorated space and embody the natural and broad decoration space. Apply the fundamental idea of Taoism thoughts and make indoor designers use the traditional representation methods so as to provide users with a kind of vivid experience and peaceful enjoyment.

Application of Buddhism Thoughts. Buddhism advocates extreme briefness and advocates individuals to express their own thoughts through direct contact and feelings. Indoor decoration's abstraction and usage of the Buddhism thoughts and culture is mainly embodied in material selection of indoor decoration. In order to show the Buddhist mood, indoor design should choose mahogany and camphorwood. The indoor design works of Buddhism can adopt the simple lines according to the pure and brief allocation principles so as to embody the strong Buddhist moods.

\section{Conclusion}

While pursuing the material comfort, people also pay attention to the spiritual pursuits of indoor environment, whose aesthetic levels keep improving. In the current days of pluralism, application of traditional Chinese cultural elements in indoor design is no longer a kind of ancient design idea. The traditional Chinese culture with rich connotations is used to provide full cognition. Combination of modern design elements and the traditional design elements can form a kind of multi-variant indoor design and decoration styles. Application of traditional Chinese culture is the duty of modern designers, for it can better inherit and develop the Chinese culture and boost the 
formation of mature indoor design styles to a great extent.

\section{Reference}

[1] Q. Li; Memory and Continuation--A Brief Analysis of Architectural Design of Suzhou Museum and Ningbo Museum [J]; Art and Design (Theory); Issue 01, 2010 (in Chinese)

[2] M.H. Li; Application of Traditional Chinese Cultural Spirits in Modern Indoor Design[J]; Research of Design Art; Issue 03, 2013 (in Chinese)

[3] W. Zhao and P.H. Wang; 'Image’ Application of Chinese Ink and Wash Art in Indoor Design [J]; Popular Literature and Art; Issue 23, 2010 (in Chinese)

[4] L. Ding; Application Research of Traditional Chinese Screen Art in Modern Architectural Space [D]; Shandong Jianzhu University; Issue 06, 2012 (in Chinese)

[5] B.B. Gao; Application of Traditional Chinese Cultural Elements in Modern Design [J]; Popular Literature and Art; Issue 23, 2010 (in Chinese)

[6] J.J. Jia; Reanalysis of Application of Traditional Lucky Decorative Patterns in Modern Indoor Design [A]; Paper Collection of China Innovative Design Yearbook; Issue 12, 2012 (in Chinese)

[7] C.M. Liao; Research of Traditional Chinese Decoration Elements in Modern Indoor Design [D]; Hubei University of Technology; 2010 (in Chinese)

[8] L. Liu. Application Research of the Batik Decoration Art of Miao Nationality in Hunan and Guizhou in Modern Indoor Design [D]; Central South University of Forestry and Technology; 2013 (in Chinese) 